\title{
Supramolecular porphyrin polymers in solution and at the solid-liquid interface
}

\author{
Richard van Hameren, ${ }^{a}$ Arend M. van Buul, ${ }^{a}$ Maria A. Castriciano, ${ }^{b}$ Valentina Villari, ${ }^{c}$ \\ Norberto Micali, ${ }^{c}$ Peter Schön, ${ }^{a}$ Sylvia Speller, ${ }^{a}$ Luigi Monsù Scolaro, ${ }^{b}$ Alan E. Rowan, ${ }^{a}$ \\ Johannes A. A. W. Elemans ${ }^{a^{*}}$ and Roeland J. M. Nolte ${ }^{a}$
}

\section{Supporting Information}

\section{Synthesis}

General.

Dichloromethane and chloroform were distilled from $\mathrm{CaH}_{2}$ prior to use. Pyrrole was purified by dry column chromatography. All other commercial chemicals were used as received. Acros alumina (activated, neutral, size $0.05-0.20 \mathrm{~mm}$ ) was used for dry column chromatography and Acros silica gel 60 (size $0.035-0.070 \mathrm{~mm}$, pore size $6 \mathrm{~nm}$ ) for column chromatography, BioRad BioBeads SX-1 were used for size-exclusion chromatography.

\section{Instrumental.}

NMR-spectra were recorded on Bruker DPX200, Bruker DMX300 or Varian Inova400 instruments. Chemical shifts are reported in ppm downfield with respect to the internal standard TMS. Maldi-TOF spectra were measured on a Bruker Biflex III spectrometer in reflection mode. The samples were prepared by mixing $10 \mu \mathrm{l}$ of dilute solutions of the porphyrin molecules in chloroform with equal amounts of matrix solution (dithranol; $20 \mathrm{mg} / \mathrm{ml}$ in chloroform) and a droplet of this mixture was put on a sample plate. Elemental analyses were determined with a Carlo Erba Ea 1108 instrument. UV-Vis spectra were measured on a Varian 
Cary 50 Conc spectrophotometer at ambient temperature. CD spectra were recorded on a Jasco 810 instrument equipped with a Peltier temperature control unit. Optical rotations were measured on a Perkin Elmer 241 Polarimeter. The specific rotation are reported in degrees, $[\alpha]_{\lambda}{ }^{\mathrm{T}}(\lambda=$ wavelength, $\mathrm{T}=$ temperature $\left.\left({ }^{\circ} \mathrm{C}\right)\right)$ together which the concentration $\left(\mathrm{c} \mathrm{in} \mathrm{g} \mathrm{ml}^{-1}\right.$ and solvent).

Compound $\mathbf{1 b}$ was synthesized as shown in scheme 1.

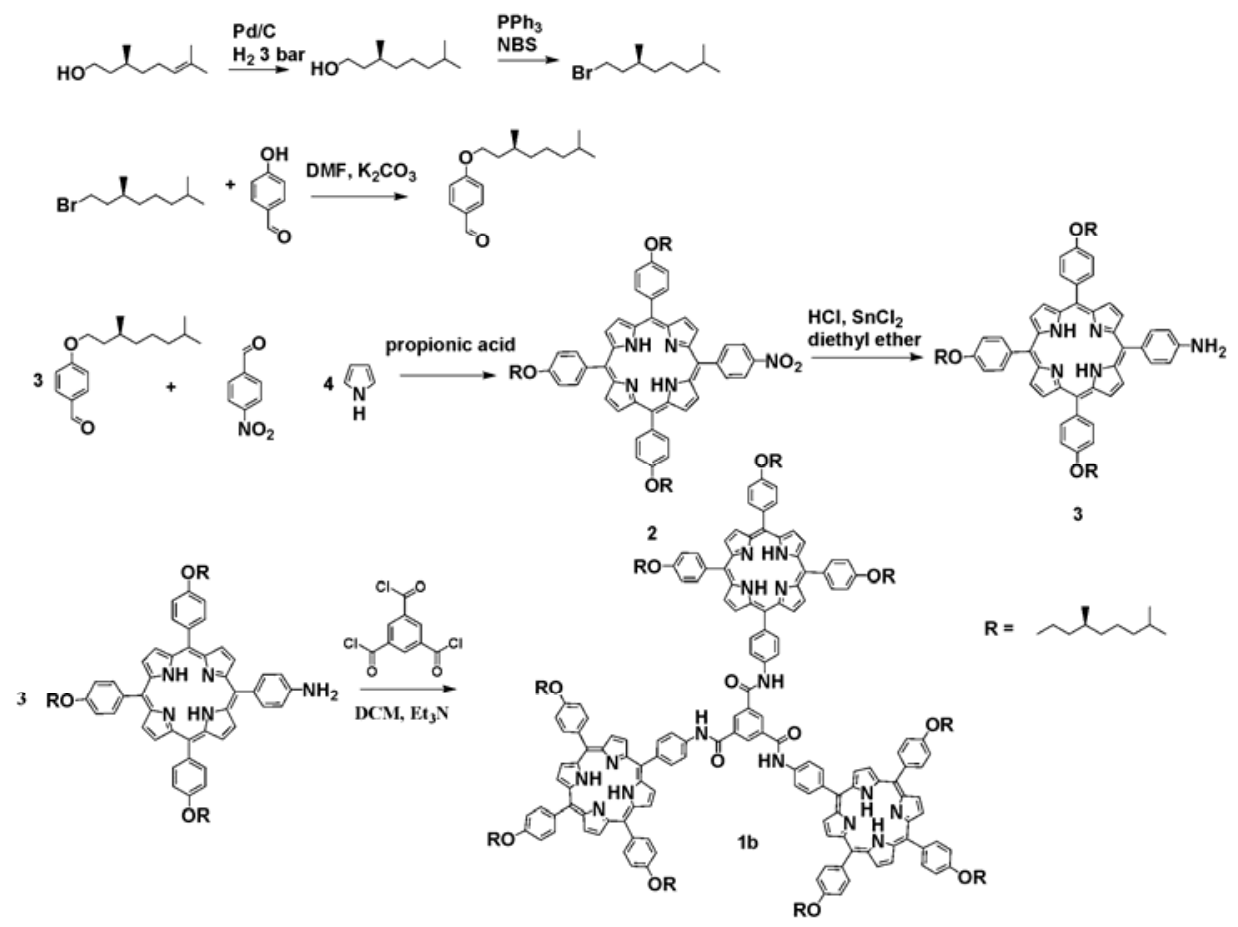

Scheme 1: Synthesis of compound $\mathbf{1 b .}$

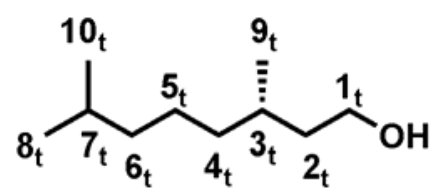

\section{(S)-3,7-Dimethyl-1-octanol}

(S)-3,7-Dimethyl-6-octen-1-ol (50.0 g, $320 \mathrm{mmol})$ and $\mathrm{Pd} / \mathrm{C}(2.0 \mathrm{~g}, 10 \% \mathrm{~mol})$ were dissolved in $60 \mathrm{ml}$ of EtOAc, after which the mixture was shaken under 3 bar of $\mathrm{H}_{2}$ pressure for $7.5 \mathrm{hrs}$. Hereafter, the $\mathrm{Pd} / \mathrm{C}$ catalyst was filtered off and the solvent was evaporated. Yield: $50.4 \mathrm{~g}(99.5$ 
\%) of product as a colorless oil. ${ }^{1} \mathrm{H}-\mathrm{NMR}\left(\mathrm{CDCl}_{3}, 200 \mathrm{MHz}\right) \delta(\mathrm{ppm}): 3.65\left(\mathrm{~m}, 2 \mathrm{H}, \mathrm{H}-\mathrm{1}_{\mathrm{t}}\right), 1.92$ $(\mathrm{s}, 1 \mathrm{H}, \mathrm{OH}), 1.64-1.10\left(\mathrm{~m}, 10 \mathrm{H}, H-2_{\mathrm{t}}-7_{\mathrm{t}}\right), 0.87\left(\mathrm{~d}, 3 \mathrm{H}, H-9_{\mathrm{t}}, J=6.5 \mathrm{~Hz}\right), 0.84\left(\mathrm{~d}, 6 \mathrm{H}, H-8_{\mathrm{t}}, 10_{\mathrm{t}}, J=\right.$ $6.6 \mathrm{~Hz}) ;[\alpha]_{\mathrm{D}}^{24}=-2.73 * 10^{-1} \mathrm{deg} \mathrm{cm}^{2} \mathrm{~g}^{-1}(c 10, \mathrm{EtOH})$.

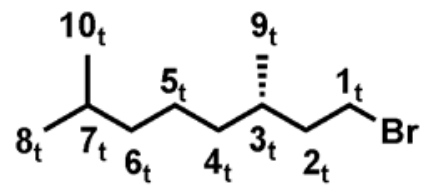

(3S)-1-Bromo-3,7-dimethyloctane

(3S)-1-Bbromo-3,7-dimethyloctane was synthesized according to the method reported by Cohen et $\mathrm{al}^{1}$. To a solution of $50.09 \mathrm{~g}(322 \mathrm{mmol})$ of 3,7-dimethyl-1-octanol and $90.5 \mathrm{~g}$ (345 mmol) of triphenylphosphine in $190 \mathrm{ml}$ of dichloromethane was added $57.32 \mathrm{~g}$ (322 mmol) of $\mathrm{N}$-bromosuccinimide in portions, while cooling the mixture on an ice bath. After stirring at room temperature for 2 hrs., the solvent was evaporated. The residue was suspended in n-hexane, this suspension was filtered, and the residue was washed thoroughly with n-hexane. Yield: $37 \mathrm{~g}(47 \%)$

${ }^{1} \mathrm{H}-\mathrm{NMR}\left(\mathrm{CDCl}_{3}, 300 \mathrm{MHz}\right) \delta(\mathrm{ppm}): 3.62\left(\mathrm{~m}, 2 \mathrm{H}, H-1_{\mathrm{t}}\right), 2.17(\mathrm{~m}, 1 \mathrm{H}, H-3 \mathrm{t}), 1.8-1.25(\mathrm{~m}, 9 \mathrm{H}$, $\left.H-2_{\mathrm{t}}, 4_{\mathrm{t}}-7_{\mathrm{t}}\right), 1.12\left(\mathrm{~m}, 9 \mathrm{H}, H-8_{\mathrm{t}}-10_{\mathrm{t}}\right) ;{ }^{13} \mathrm{C}-\mathrm{NMR}\left(\mathrm{CDCl}_{3}, 50 \mathrm{MHz}\right) \delta(\mathrm{ppm}): 40.18\left(\mathrm{C1}_{\mathrm{t}}\right), 39.26\left(\mathrm{C6}_{\mathrm{t}}\right)$, $36.82\left(\mathrm{C4}_{\mathrm{t}}\right), 31.72\left(\mathrm{C} 2_{\mathrm{t}}\right), 31.27\left(\mathrm{C} 3_{\mathrm{t}}\right), 28.00\left(\mathrm{C} 7_{\mathrm{t}}\right), 24.65\left(\mathrm{C} 5_{\mathrm{t}}\right), 22.63\left(\mathrm{C} 8_{\mathrm{t}}\right), 22.53\left(\mathrm{C} 10_{\mathrm{t}}\right), 18.88$ $\left(\mathrm{C} 9_{\mathrm{t}}\right) ;[\alpha]^{24}=-3.5 * 10^{-1} \mathrm{deg} \mathrm{cm}^{2} \mathrm{~g}^{-1}($ c 10, EtOH $)$.

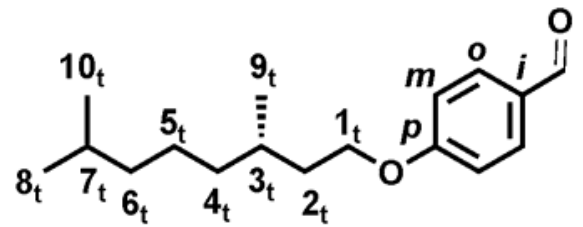

(3S)-4-(3,7-Dimethyloctoxy)benzaldehyde

p-Hydroxybenzaldehyde $16.9 \mathrm{~g}(137 \mathrm{mmol})$ and $33.21 \mathrm{~g}(150 \mathrm{mmol})$ of (3S)-1-bromo-3,7dimethyloctane were dissolved in $140 \mathrm{ml}$ of DMF. After adding $60 \mathrm{~g}$ of $\mathrm{K}_{2} \mathrm{CO}_{3}$, the mixture was 
refluxed for 3 hrs. After cooling and filtration, the solution was concentrated and the residue purified by column chromatography on silica (eluent: $n$-hexane/EtOAc $(8: 1, \mathrm{v} / \mathrm{v})$. The second fraction was the desired compund. Yield: $26.26 \mathrm{~g}(60 \%)$ of product as a colorless oil. ${ }^{1} \mathrm{H}-\mathrm{NMR}$ $\left(\mathrm{CDCl}_{3}, 200 \mathrm{MHz}\right) \delta(\mathrm{ppm}): 9.86(\mathrm{~s}, \mathrm{CHO}, 1 \mathrm{H}), 7.83$ (d, $\mathrm{CH}$ o-Ph, 2H, J = $\left.8.3 \mathrm{~Hz}\right), 7.00$ (d, CH $m-\mathrm{Ph}, 2 \mathrm{H}, J=8.6 \mathrm{~Hz}), 4.07\left(\mathrm{t}, H-1_{\mathrm{t}}, 2 \mathrm{H}, J=6.5 \mathrm{~Hz}\right), 1.84(\mathrm{~m}, 2 \mathrm{H}, H-2 \mathrm{t}, J=6.8 \mathrm{~Hz}), 1.37-1.14$ $\left(\mathrm{m}, 8 \mathrm{H}, H-3_{\mathrm{t}}-7_{\mathrm{t}}\right), 0.95\left(\mathrm{~d}, 3 \mathrm{H}, H-9_{\mathrm{t}}, J=6.3 \mathrm{~Hz}\right), 0.87\left(\mathrm{~d}, 6 \mathrm{H}, H-8_{\mathrm{t},} 10_{\mathrm{t}} J=6.6 \mathrm{~Hz}\right) ;{ }^{13} \mathrm{C}-\mathrm{NMR}$ $\left(\mathrm{CDCl}_{3}, 50 \mathrm{MHz}\right) \delta(\mathrm{ppm}): 190.57(\mathrm{Ph}-\mathrm{CO}), 164.10(i-\mathrm{Ph}) 131.83(o-\mathrm{Ph}), 129.63(p-\mathrm{Ph}), 114.62$ $(m-\mathrm{Ph}), 66.62\left(\mathrm{Cl}_{\mathrm{t}}\right), 39.10,37.13,35.85,27.86,24.55,22.61\left(\mathrm{C} 2{ }_{\mathrm{t}}-\mathrm{C} 7_{\mathrm{t}}\right), 22.69\left(2 \mathrm{C}, \mathrm{C} 8_{\mathrm{t}}, \mathrm{C} 10_{\mathrm{t}}\right)$, $19.82\left(\mathrm{C} 9_{\mathrm{t}}\right) ;[\alpha]^{24}=-6.4 * 10^{-1} \mathrm{deg} \mathrm{cm}^{2} \mathrm{~g}^{-1}(c \mathrm{c} 1.03, \mathrm{EtOH})$.

21H,23H-5-p-Nitrophenyl-10,15,20-tris-(p-(S)-3,7-dimethyloctoxyphenyl)porphyrin (2) (3S)-4-(3,7-Dimethyloctoxy)benzaldehyde (8.0 g, $30.5 \mathrm{mmol})$, p-nitrobenzaldehyde (1.6 g $10.9 \mathrm{mmol})$, and pyrrole $(2.1 \mathrm{~g}, 40 \mathrm{mmol})$ were dissolved in propionic acid (200 $\mathrm{ml})$ and the solution was refluxed for 2 hrs. The solvent was removed under vacuum and the product was purified by column chromatography (eluent dichloromethane), yielding a purple solid. Yield: $230 \mathrm{mg}(3 \%)$.

${ }^{1} \mathrm{H}-\mathrm{NMR}\left(\mathrm{CDCl}_{3}, 400 \mathrm{MHz}\right): \delta(\mathrm{ppm}): 8.92$ (d, 2H, H-2,8- $\beta$-pyrrole, $\left.J=4.7 \mathrm{~Hz}\right), 8.93$ (s, 4H, H12,13,17,18- $\beta$-pyrrole), 8.75 (d, 2H, H-3,7 $\beta$-pyrrole, $J=4.9 \mathrm{~Hz}$ ), 8.57 (d, 2H, CH m-Ph- $\mathrm{NO}_{2}, J=$ $8.8 \mathrm{~Hz}), 8.34\left(\mathrm{~d}, 2 \mathrm{H}, \mathrm{CH} o-\mathrm{Ph}-\mathrm{NO}_{2}, J=8.8 \mathrm{~Hz}\right), 8.12,8.10$ (dd, $6 \mathrm{H}, \mathrm{CH}$ o-Ph-OC $\mathrm{OC}_{10} \mathrm{H}_{21}, J=8.6$ Hz), $7.28\left(\mathrm{~d}, 6 \mathrm{H}, \mathrm{CH} m-\mathrm{Ph}-\mathrm{OC}_{10} \mathrm{H}_{21}, J=8.6 \mathrm{~Hz}\right), 4.28\left(\mathrm{t}, 6 \mathrm{H}, H-1_{\mathrm{t}}, J=6.3 \mathrm{~Hz}\right), 1.84(\mathrm{~m}, 6 \mathrm{H}, H-$ $\left.2_{\mathrm{t}}, J=6.8 \mathrm{~Hz}\right), 1.37-1.14\left(\mathrm{~m}, 24 \mathrm{H}, H-3_{\mathrm{t}}-7_{\mathrm{t}}\right), 0.95\left(\mathrm{~d}, 9 \mathrm{H}, H-9_{\mathrm{t}}, J=6.3 \mathrm{~Hz}\right), 0.87\left(\mathrm{~d}, 12 \mathrm{H}, H-8_{\mathrm{t}}, 10_{\mathrm{t}}\right.$, $J=6.6 \mathrm{~Hz}),-2.65$ (s, broad, $2 \mathrm{H}, \mathrm{NH}$-porphyrin). ${ }^{13} \mathrm{C}-\mathrm{NMR}\left(\mathrm{CDCl}_{3}, 50 \mathrm{MHz}\right): \delta=159.6(3 \mathrm{C}, p-$ Ph- $\left.-\mathrm{OC}_{10} \mathrm{H}_{21}\right), 149.6\left(1 \mathrm{C}, p-\mathrm{Ph}-\mathrm{NO}_{2}\right), 148.1$ (1C, i-Ph- $\left.\mathrm{NO}_{2}\right), 136.0$ (3C, o-Ph-OC $\left.{ }_{10} \mathrm{H}_{21}\right), 135.6(2 \mathrm{C}$, o-Ph- $\left.\mathrm{NO}_{2}\right), 134.4\left(1 \mathrm{C}, 15-\mathrm{i}-\mathrm{Ph}-\mathrm{OC}_{10} \mathrm{H}_{21}\right), 134.3$ (2C, 10,20-i-Ph- $\left.\mathrm{OC}_{10} \mathrm{H}_{21}\right), 131.8$ (8C, broad, $\beta$ pyrrole), $122.1\left(2 \mathrm{C}, m-\mathrm{Ph}-\mathrm{NO}_{2}\right), 121.4\left(1 \mathrm{C}, \mathrm{C}_{15}\right), 120.9\left(2 \mathrm{C}, \mathrm{C}_{10,20}\right), 116.8\left(1 \mathrm{C}, \mathrm{C}_{5}\right), 113.2(6 \mathrm{C}, \mathrm{m}-$ 
Ph- $\left.\mathrm{OC}_{10} \mathrm{H}_{21}\right), 67.1\left(\mathrm{C1}_{\mathrm{t}}\right), 39.7\left(\mathrm{C6}_{\mathrm{t}}\right), 37.8\left(\mathrm{C}_{\mathrm{t}}\right), 36.8\left(\mathrm{C}_{\mathrm{t}}\right), 30.4\left(\mathrm{C}_{\mathrm{t}}\right), 28.4\left(\mathrm{C}_{\mathrm{t}}\right), 25.1\left(\mathrm{C}_{\mathrm{t}}\right)$, $22.9\left(\mathrm{C}_{\mathrm{t}}\right), 22.8\left(\mathrm{C} 10_{\mathrm{t}}\right), 19.9\left(\mathrm{C} 9_{\mathrm{t}}\right)$. MALDI-TOF: $\mathrm{M}^{+}=1127.4$, calculated: 1127.7.

\section{H,23H-5-p-Aminophenyl-10,15,20-tris-(p-(S)-3,7-dimethyloctoxyphenyl)porphyrin} (3).

$\mathrm{SnCl}_{2} \cdot \mathrm{H}_{2} \mathrm{O}(2 \mathrm{~g}, 8 \mathrm{mmol})$ and $2(200 \mathrm{mg}, 0.16 \mathrm{mmol})$ were dissolved in $200 \mathrm{ml}$ of $\mathrm{HCl}$-saturated diethyl ether. The mixture was stirred in the dark for $48 \mathrm{hrs}$. and then $200 \mathrm{ml}$ of an aqueous 3M $\mathrm{NaOH}$ solution was added. The organic layer was separated and washed with an aqueous sat. $\mathrm{NaHCO}_{3}$ solution, with brine $(3 \mathrm{x})$, and dried over $\mathrm{MgSO}_{4}$. After filtration and removal of the solvent a purple solid was obtained, which was purified by column chromatography (eluent toluene). Yield: $163 \mathrm{mg}(81 \%)$.

${ }^{1} \mathrm{H}-\mathrm{NMR}\left(\mathrm{CDCl}_{3}, 200 \mathrm{MHz}\right): \delta(\mathrm{ppm}): 8.86$ (m, broad, 8H, $\beta$-pyrrole), 8.13 (d, 6H, CH o-Ph$\left.\mathrm{OC}_{10} \mathrm{H}_{21}, J=8.6 \mathrm{~Hz}\right), 8.06$ (d, 2H, CH o-Ph-NH $\left.\mathrm{NH}_{2}, J=8.3 \mathrm{~Hz}\right), 7.24$ (d, 6H, CH o-Ph-OC ${ }_{10} \mathrm{H}_{21}, J=$ $8.3 \mathrm{~Hz}), 7.05$ (d, 2H, CH m-Ph-NH $\mathrm{NH}_{2}, J .3 \mathrm{~Hz}$ ), 4.27 (t, 6H, H-1 $\left.{ }_{\mathrm{t}}, J=6,2 \mathrm{~Hz}\right), 4.00$ (s, 2H, NH${ }_{2}$, $1.97-0.88$ (m, 19H, $\left.H-2_{\mathrm{t}}-10_{\mathrm{t}}\right),-2.74$ (s, broad, $2 \mathrm{H}, \mathrm{NH}$-porphyrin). ${ }^{13} \mathrm{C}-\mathrm{NMR}\left(\mathrm{CDCl}_{3}, 50 \mathrm{MHz}\right): \delta$ $=158.9\left(i-\mathrm{Ph}-\mathrm{OC}_{10} \mathrm{H}_{21}\right), 145.89\left(\mathrm{i}-\mathrm{Ph}-\mathrm{NH}_{2}\right), 135.59\left(o-\mathrm{Ph}-\mathrm{OC}_{10} \mathrm{H}_{21}\right), 134.5\left(o-\mathrm{Ph}_{-} \mathrm{NH}_{2}\right), 131.05$ (broad, $\mathrm{CH} \beta$-pyrrole), $113.4\left(m-\mathrm{Ph}-\mathrm{NH}_{2}\right), 112.7\left(m-\mathrm{Ph}-\mathrm{OC}_{10} \mathrm{H}_{21}\right), 66.6\left(\mathrm{Cl}_{\mathrm{t}}\right), 39.3\left(\mathrm{C6}_{\mathrm{t}}\right), 37.4$ $\left(\mathrm{C4} 4_{\mathrm{t}}\right), 36.4\left(\mathrm{C} 2_{\mathrm{t}}\right), 30.0\left(\mathrm{C} 3_{\mathrm{t}}\right), 28.0\left(\mathrm{C} 7_{\mathrm{t}}\right), 24.8\left(\mathrm{C5} \mathrm{t}_{\mathrm{t}}\right), 22.8\left(\mathrm{C} 8_{\mathrm{t}}\right), 22.7\left(\mathrm{C} 10_{\mathrm{t}}\right), 19.8\left(\mathrm{C} 9_{\mathrm{t}}\right)$.

\section{Chiral porphyrin trimer (1b)}

Compound 3 (163 mg $0.13 \mathrm{mmol})$ and a drop of distilled pyridine were dissolved in $25 \mathrm{ml}$ of dichloromethane under a nitrogen atmosphere. At $0^{\circ} \mathrm{C}$, trimesoyl chloride $(10.8 \mathrm{mg}, 0.04 \mathrm{mmol})$ was added and the mixture was stirred for 2 hrs while it was allowed to warm to room temperature. The solvent was removed under vacuum and the product was purified by column 
chromatography (eluent: $1 \%$ methanol in chloroform) followed by size-exclusion chromatography (eluent: toluene). Yield: $95 \mathrm{mg}$ (86\%).

${ }^{1} \mathrm{H}-\mathrm{NMR}\left(\mathrm{CDCl}_{3}\right.$ with a droplet of DMSO-d6, $\left.400 \mathrm{MHz}\right): \delta=10.33$ (s, broad, $3 \mathrm{H}, \mathrm{NH}$ amide) 9.10 (s, 3H CH central benzene), 8.85 (d, broad, 6H, H-C3,7- $\beta$-pyrrole, $J=4.8 \mathrm{~Hz}$ ), 8.80 (d, 6H, broad $H$-C2,8- $\beta$-pyrrole, $J=4.8 \mathrm{~Hz}$ ), 8.78 (s, broad, $12 \mathrm{H}, H$-C12,13,17,18- $\beta$-pyrrole), 8.28 (d, 6H, CH o-Ph-NH, J = 8.0 Hz), 8.23 (d, 6H, CH m-Ph-NH, J = 8.4 Hz), 8.19 (d, 18H, CH o-Ph$\left.\mathrm{OC}_{10} \mathrm{H}_{21}, J=8.4 \mathrm{~Hz}\right), 8.00\left(\mathrm{t}, 18 \mathrm{H}, \mathrm{CH} m-\mathrm{Ph}-\mathrm{OC}_{12} \mathrm{H}_{25}, J=7.4 \mathrm{~Hz}\right), 4.20\left(\mathrm{t}, 18 \mathrm{H}, H-1_{\mathrm{t}}, J=5,2\right.$ $\mathrm{Hz}), 1.93\left(\mathrm{~m}, 9 \mathrm{H}, H-4_{\mathrm{t}}\right), 1.75\left(\mathrm{~m}, 9 \mathrm{H}, H-3_{\mathrm{t}}\right), 1.70\left(\mathrm{~m}, 18 \mathrm{H}, H-4_{\mathrm{t}}\right), 1.50\left(\mathrm{~m}, 18 \mathrm{H}, H-7_{\mathrm{t}}\right), 1.34(\mathrm{~m}$, 18H, H-5 $\mathrm{t}_{\mathrm{t}}, 1.28\left(\mathrm{~m}, 9 \mathrm{H}, H-2_{\mathrm{t}}\right), 1.21\left(\mathrm{~m}, 18 \mathrm{H}, H-7_{\mathrm{t}}\right), 1.15\left(\mathrm{~m}, 18 \mathrm{H}, H-6_{\mathrm{t}}\right), 0.97\left(\mathrm{~m}, 27 \mathrm{H}, H-9_{\mathrm{t}}\right)$, $0.82\left(\mathrm{~m}, 54 \mathrm{H}, \mathrm{H}-8_{\mathrm{t}}, 10_{\mathrm{t}}\right) \cdot{ }^{13} \mathrm{C}-\mathrm{NMR}\left(\mathrm{CD}_{2} \mathrm{Cl}_{2}\right.$ with a droplet of DMSO-d6, $\left.75 \mathrm{MHz}\right): \delta(\mathrm{ppm}): 190.0$ $(3 \mathrm{C}, \mathrm{C}=\mathrm{O}), 165.6(\mathrm{CH}-\mathrm{C}=\mathrm{O}$ central benzene $), 159.5\left(\mathrm{C} 15-p-\mathrm{Ph}-\mathrm{OC}_{10} \mathrm{H}_{21}\right), 159.1(\mathrm{C} 10,20-p-\mathrm{Ph}-$ $\left.\mathrm{OC}_{10} \mathrm{H}_{21}\right), 147.5$ (C5-p-Ph-NH), 136.6 (C5-o-Ph-NH), 135.9 (C15-o-Ph-OC $\left.{ }_{10} \mathrm{H}_{21}\right), 135.6$ (C10,20$\left.o-\mathrm{Ph}-\mathrm{OC}_{10} \mathrm{H}_{21}\right), \quad 134,5\left(\mathrm{C} 15-\mathrm{i}-\mathrm{Ph}-\mathrm{OC}_{10} \mathrm{H}_{21}\right), 134.2\left(\mathrm{C} 10,20-i-\mathrm{Ph}-\mathrm{OC}_{10} \mathrm{H}_{21}\right), 131.3$ (broad, $\beta$ pyrrole), 130.5 (broad, $\beta$-pyrrole), 120.5 (C15), 120.2 (C10,20), 119.6 (C5), 119.5 (C5-m-Ph$\mathrm{NH}), 113.1\left(\mathrm{C} 15-m-\mathrm{Ph}-\mathrm{OC}_{10} \mathrm{H}_{21}\right), 112.7\left(\mathrm{C} 10,20-m-\mathrm{Ph}-\mathrm{OC}_{10} \mathrm{H}_{21}\right), 67.1\left(\mathrm{C} 15-\mathrm{C} 1_{\mathrm{t}}\right), 66.7(\mathrm{C} 10,20-$ $\left.\mathrm{C1} 1_{\mathrm{t}}\right), 39.7\left(\mathrm{C6}_{\mathrm{t}}\right) 37.7\left(\mathrm{C4}_{\mathrm{t}}\right), 36.7\left(\mathrm{C}_{\mathrm{t}}\right), 30.4\left(\mathrm{C3}_{\mathrm{t}}\right), 30.3\left(\mathrm{C3}_{\mathrm{t}}\right), 30.0\left(\mathrm{C} 3_{\mathrm{t}}\right), 28.4\left(\mathrm{C} 7_{\mathrm{t}}\right), 25.1\left(\mathrm{C} 5_{\mathrm{t}}\right), 22.9$ $\left(\mathrm{C} 8_{\mathrm{t}}\right), \quad 22.8\left(\mathrm{C} 10_{\mathrm{t}}\right), \quad 19.9\left(\mathrm{C} 9_{\mathrm{t}}\right)$. MALDI-TOF: $\mathrm{M}^{+}=3452.2$, calculated: 3451.7. Elemental analysis: Calculated for $\mathrm{C}_{231} \mathrm{H}_{273} \mathrm{~N}_{15} \mathrm{O}_{12} \cdot \mathrm{H}_{2} \mathrm{O}$ : C (79.96\%), H (7.99\%) N (6.06\%). Found: C (79.33\%), H (7.90\%), N (5.94\%).

\section{DLS and SLS measurements}

In the experimental set-up for Dynamic and Static Light Scattering a He-Ne laser $\left(\lambda_{0}=632.8 \mathrm{~nm}\right.$, with a power of $10 \mathrm{~mW}$ ) is used as laser source; the beam, linearly polarized orthogonally to the scattering plane, is focused on the sample. The light scattered from the sample is collected by a 
cooled photomultiplier Hamamatsu R943-02 at different scattering angles ( $\theta)$, which are set by a computer-controlled goniometer. An interference filter, inserted in the collecting path, eliminates unwanted contributions from fluorescence.

For the static light-scattering measurements, the intensity scattered from the sample is corrected for the solvent contribution and then normalized by the absolute scattered intensity of toluene used as reference. The absolute scattered intensity can be written as: ${ }^{1}$

$I(Q)=K M_{w} c P(Q) S(Q)$

$P(Q)$ and $S(Q)$ are the normalized form factor and the structure factor, respectively $\left(\mathrm{Q}=\left(4 \pi \mathrm{n} / \lambda_{0}\right) \sin (\theta / 2)\right.$ being the exchanged wavevector, $\mathrm{n}$ being the refractive index of the medium), $M_{w}$ is the molecular weight, $c$ is the mass concentration, and $K$ is the optical constant.

For the scattering geometry of the experiment, it is $K=\frac{4 \pi^{2} n^{2}}{\lambda_{0}^{4} N_{A}}\left(\frac{d n}{d c}\right)^{2}, N_{A}$ being the Avogadro number and $\mathrm{dn} / \mathrm{dc}$ the refractive index increment. It can be considered that, for the solutions investigated, the concentration is low enough that $S(Q)$ can be approximated to unity.

For the dynamic-light scattering measurements, the scattered light, collected in a self-beating mode, is analyzed by a MALVERN 4700 correlator which builds up the intensity autocorrelation function: ${ }^{2}$

$g_{2}(Q, t)=\frac{\langle I(Q, 0) I(Q, t)\rangle}{\langle I(0)\rangle^{2}}$

For diffusing monodisperse spherical scatterers with hydrodynamic radius $R_{\mathrm{H}}$, such as $Q R_{\mathrm{H}}<<1$, the intensity autocorrelation function takes a simple exponential form, $g_{2}(Q, t)=1+\exp (-2 \Gamma t)$ with $\Gamma=D Q^{2}$ ( $D$ being the collective diffusion coefficient). In the case that $Q R_{\mathrm{H}}>>1$, previous form for the autocorrelation function holds provided that the diffusion objects are rigid. 
Because the investigated solutions are slightly polydisperse, the autocorrelation functions have been analyzed in terms of a standard cumulant analysis ${ }^{1,2}$ to find a mean diffusion coefficient, $D_{\text {eff: }}$

$\ln \left|g_{1}(Q, t)\right|=-D_{\text {eff }} Q^{2} t+1 / 2 ! \mu_{2} t^{2}-1 / 3 ! \mu_{3} t^{3}+\ldots$

with $\mu_{\mathrm{n}}$ the moments of the distribution of the decay rates (the quantity $\mu_{2}$ is related to the size polydispersity of the particles).

It can be considered that, for the solutions investigated, the concentration is low enough that the mean diffusion coefficient $D_{\text {eff }}$ can be identified with the diffusion coefficient at infinite dilution $D_{0}$. The latter is related to the hydrodynamic radius of the particle by Einstein-Stokes relation $\mathrm{D}_{0}=k_{\mathrm{B}} T /\left(6 \pi \eta R_{\mathrm{H}}\right), k_{\mathrm{B}}$ being the Boltzmann's constant, $T$ the absolute temperature, and $\eta$ the solvent viscosity.

For non-spherical particles $R_{H}$ represents the radius of an equivalent sphere possessing the same translation diffusion coefficient; in this case detailed information on the shape requires the complementary Static Light Scattering measurements. ${ }^{3}$

\section{Time-resolved fluorescence}

Luminescence and resonance light scattering (RLS) spectra were recorded on a Jasco FP750 spectrofluorimeter equipped with a Hamamatsu R928 phototube adopting a synchronous scan protocol for RLS experiments. ${ }^{4}$ The emission spectra were not corrected for the absorption of the samples. The fluorescence measurements were carried out on a home-made time-correlated-single-photon-counting (TCSPC) 5 apparatus, which has been described elsewherethe. ${ }^{6}$ The fluorescence decay profiles were analyzed through a nonlinear least-squares iterative deconvolution procedures based on the Marquardt algorithm, ${ }^{7}$ achieving an instrumental resolution of a few tens of picoseconds. The total fluorescence decay curves were fitted to a multi-exponential decay equation: ${ }^{8}$

$$
I(t)=I_{0} \sum_{i} \alpha_{i} \exp \left(-t / \tau_{i}\right)
$$

Eq. 1 
where $I(t)$ is total fluorescence decay curve, $I_{0}$ the intensity at $t=0$ and $\alpha_{i}$ and $\tau_{i}$ are the relative amplitude and the lifetime of $i$-th component (the normalization condition being $\left.\sum_{i} \alpha_{i}=1\right)$, respectively. Fluorescence anisotropy, $r(t)$, is defined according to the following equation:

$$
r(t)=\frac{I_{V V}(t)-I_{V H}(t)}{I_{V V}(t)+2 I_{V H}(t)}
$$

where $V V$ and $V H$ indicate the vertically and horizontally polarized emission, with the

excitation beam being vertically polarized. Since, in our experimental conditions, the anisotropy decay times were much longer than the overall instrumental response $(\sim 200$ ps), no deconvolution procedure was applied and the $r(t)$ curves were simply fitted to the following exponential decay equation:

$$
r(t)=r_{0} \exp \left(-t / \tau_{R}\right)
$$

where $r_{0}$ is the limiting anisotropy and $\tau_{\mathrm{R}}$ the rotational correlation time. Assuming a simple case of "spherical molecules", $\tau_{\mathrm{R}}$ is related to the volume $V$ of the equivalent sphere by:

$$
\tau_{R}=\frac{\eta V}{k_{B} T}
$$

with $\eta$ the microviscosity of the medium, $T$ the temperature in $\mathrm{K}$ and $k_{B}$ the Boltzmann constant. In the presence of aggregates fluorescence is also polarized due to the fact that the aggregate rotation correlation time is much larger than fluorescence lifetimes. In this case equation (3) becomes:

$r(t)=r_{0} \exp \left(-t / \tau_{R}\right)+r_{0 \infty}$

where $r_{0 \infty}$ is the asymptotic anisotropy.

\section{Atomic Force Microscopy.}

For AFM measurements a Nanoscope IV with Dimension 3100 (Veeco / digital instruments, Santa Barbara, California) was used. Tapping in air was performed with $100 \mu \mathrm{m}$ long standard 
silicon tips (NSG 10, ND-MDT, Moscow, Zelenograd, Russia) with average nominal resonant frequencies of $255 \mathrm{kHz}$ and average nominal force constants of $11.5 \mathrm{~N} / \mathrm{m}$. Scanning was performed at a speed of $0.3-1.0$ lines/s with amplitude setpoints of $1.5-2 \mathrm{~V}$. Standard software (Nanoscope, version $6.12 \mathrm{r} 3)$ was used for image processing $\left(1^{\text {st }}\right.$ and $2^{\text {nd }}$ order flattening) and analysis. A droplet $(3 \mu \mathrm{l})$ of a solution of $\mathbf{1 b}$ in chloroform or $\mathrm{n}$-hexane was placed onto freshly cleaved mica. After evaporation of the solvent the sample was measured by tapping mode AFM. All evaporation experiments were carried out in a controlled environment, in which the temperature was $22 \pm 0.5 \mathrm{oC}$, in argon atmosphere.

\section{Statistics}

The spatial distribution of assemblies of $\mathbf{1 b}$ within single domains was determined by AFM measurements. All these measurements were combined and analysed with help of a Gaussian fit (Origin 7.5). A similar approach yielded the height of the aggregates. The length of the aggregates in n-hexane was determined by the usage of "scanning adventure", an analysis program by J. Barbet. ${ }^{8}$ The length distribution was determined with the help of a Gaussian fit (Origin 7.5)

\section{Spectral deconvolution}

UV-Vis and CD-spectra were deconvoluted by fitting the absorption and dichroic bands in Origin 7.5 using a Lorentzian peak function. 


\section{Supporting figure 1: deconvoluted UV-vis spectra}

A)

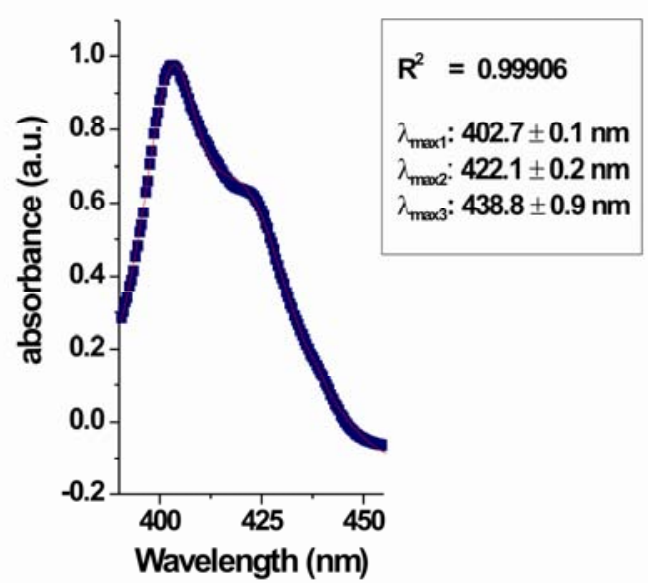

B)

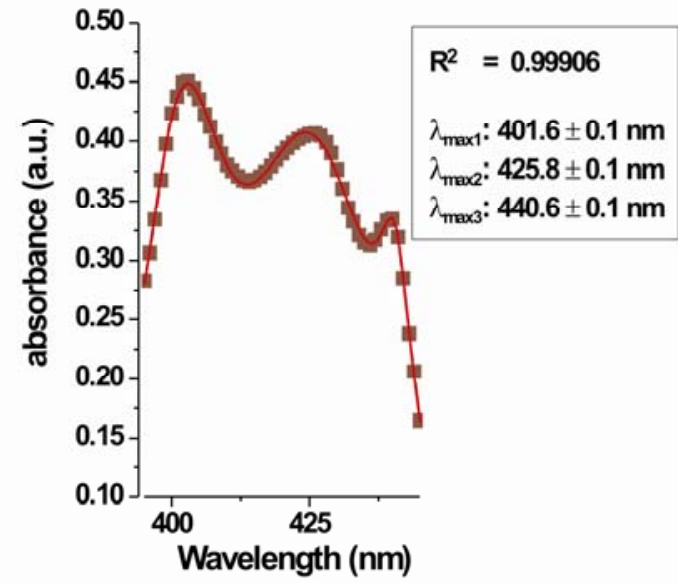

Deconvoluted UV-Vis-spectra of $\mathbf{1 b}$ in $n$-hexane $(A)$ and cyclohexane $(B)\left(\lambda_{\max }=\right.$ wavelength of the absorbance band).

\section{Supporting figure 2: deconvoluted CD spectra}

A)

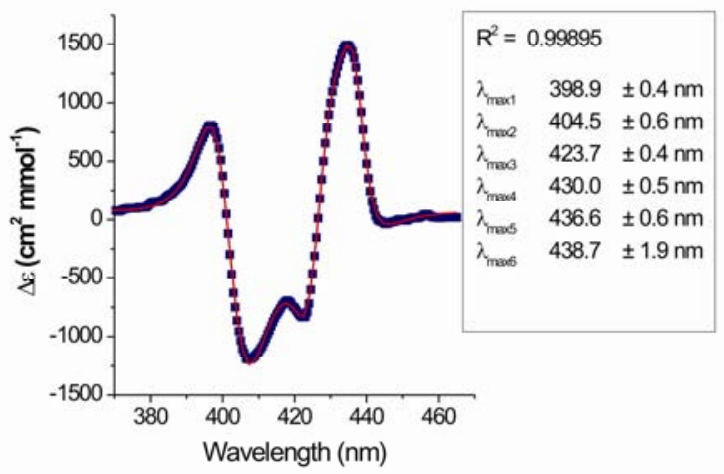

B)

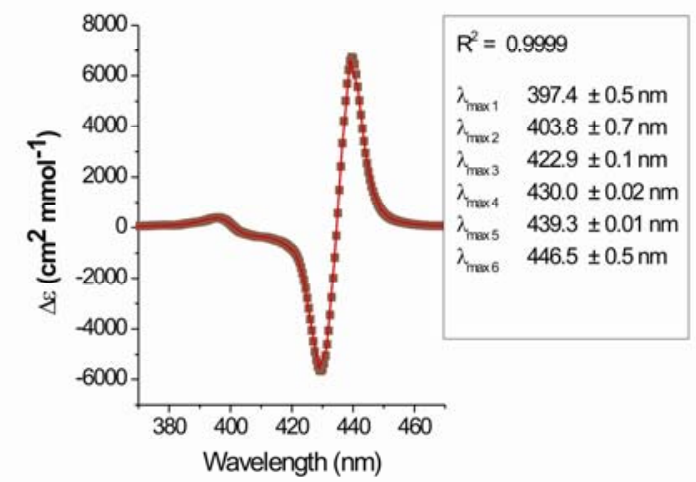

Deconvoluted CD-spectra of $\mathbf{1 b}$ in (A) n- hexane with Cotton effects at 402, 427 and 438 $\mathrm{nm}$; (B) cyclohexane with Cotton effects at 401, 426 and $443 \mathrm{~nm} ; \lambda_{\max }=$ wavelength of maximum of dichroism.. 


\section{Supporting figure 3: deconvoluted spectra at $\mathrm{T}=41^{\circ} \mathrm{C}$ in $\mathrm{n}$-hexane}

A)

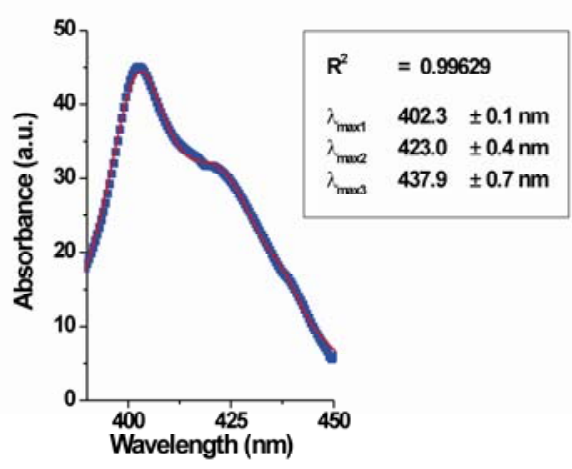

B)

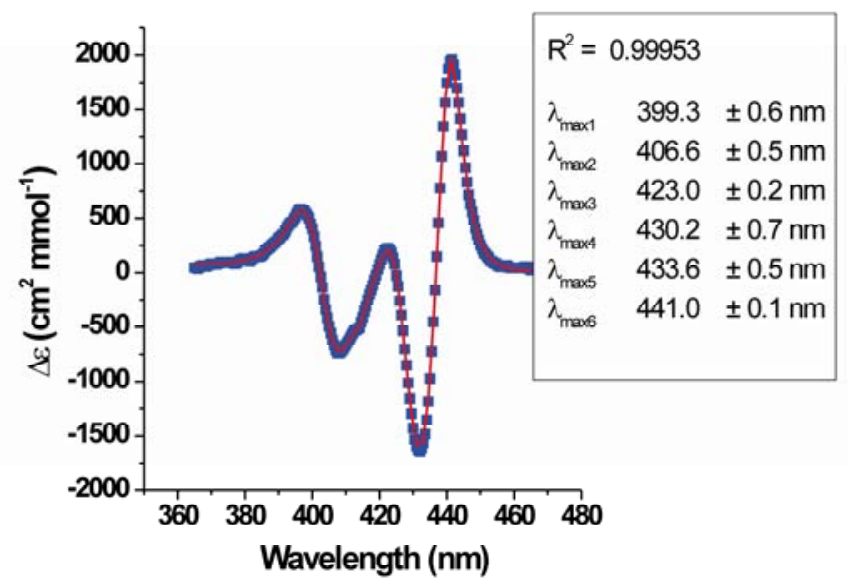

Deconvoluted UV-vis spectrum of $\mathbf{1 b}$ in n-hexane $\left([\mathbf{1 b}]==2.9 \times 10^{-5} \mathrm{M}\right)$ at $41{ }^{\circ} \mathrm{C}$. (B) Deconvoluted CD-spectum of $\mathbf{1 b}$ in n-hexane $\left([\mathbf{1 b}]==2.9 \times 10^{-5} \mathrm{M}\right)$ at $41{ }^{\circ} \mathrm{C}$ with Cotton effects at 403, 426 and $437 \mathrm{~nm} ; \lambda_{\max }=$ wavelength of maximum of dichroism.

\section{Supporting figure 4: statistics on the linear patterns of $\mathbf{1 b}$ formed at a} mica-chloroform interface as determined by AFM.

A)

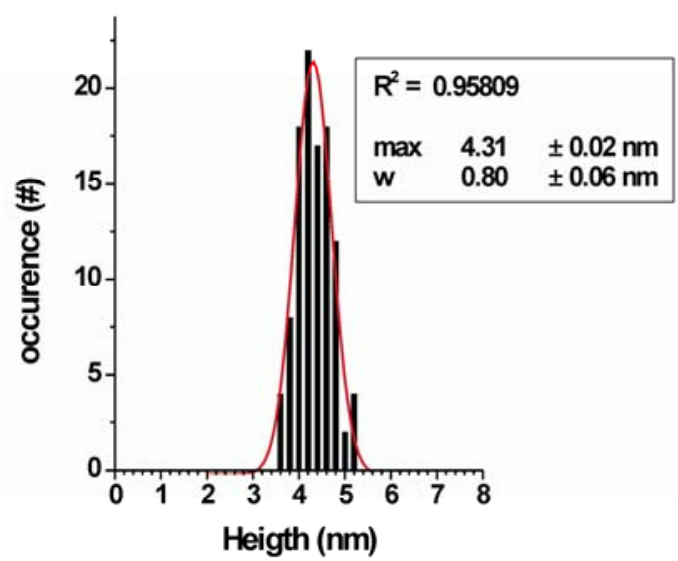

B)

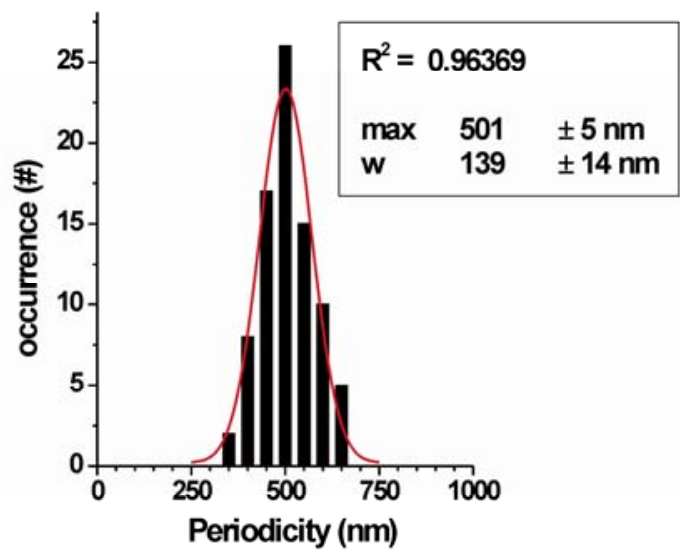

A) The height of the lines in chloroform amounted to $4.31 \mathrm{~nm}$ with $\sigma=0.4 \mathrm{~nm} \mathrm{~B}$ ) The periodicity of the pattern was $500 \mathrm{~nm}$ with $\sigma=70 \mathrm{~nm}$ (width of peak $(\mathrm{w})=2 \sigma$ ). 


\section{Supporting figure 5: statistics on the assemblies of $\mathbf{1 b}$ formed at an $\mathbf{n -}$ hexane/mica interface as determined by AFM.}

A)

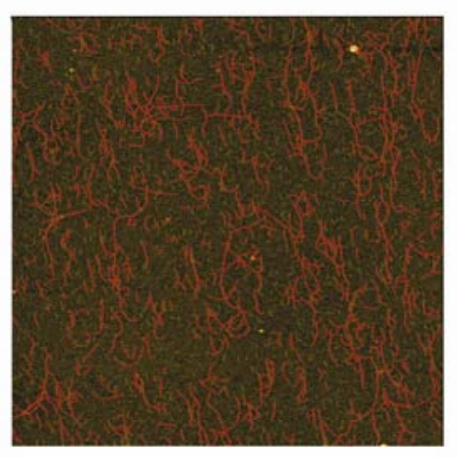

B)

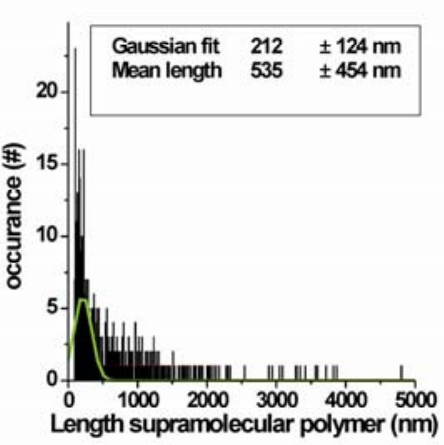

C)

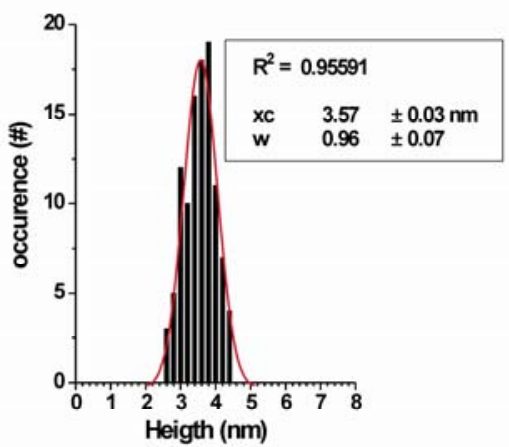

A) Overview of the data selection by the Scanning Adventure Software. ${ }^{9}$ B) Distribution diagram of the length of aggregates of $\mathbf{1 b}$ as determined from the AFM image in supporting figure 5A. The mean length of the stack of $\mathbf{1 b}$ was found to be $535 \mathrm{~nm}$, however, the distribution of the lengths is very broad. Gaussian fitting of the apparent maximum in the length distribution demonstrated that the majority of the aggregates has a length in the range of 100-325 nm. C) The height distribution obtained from AFM measurements. The distribution was fitted assuming a Gaussian distribution and yielded a height of $3.6 \mathrm{~nm}$ with $\sigma=0.5 \mathrm{~nm}$ (width of peak $(\mathrm{w})=2 \sigma$ ).

\section{Supporting references}

1. Chu, B. Laser Light Scattering-Basic Principle and Practice, $2^{\text {nd }}$ ed.; Academic: San Diego, CA, 1991.

2. Berne, B. J.; Pecora, R. Dynamic Light Scattering; Wiley-Interscience: New York, 1976.

3. Zero, K.; Pecora, R. Application of Photon Correlation Spectroscopy. In Dynamic Light Scattering; Pecora, R., Ed.; Plenum Press: New York, 1985; p 59. 
4. Pasternack, R. F.; Collings, P. J. Science 1995, 269, 935.

5. O'Connor, D. V.; Phillips, D.; Time-Correlated Single Photon Counting; Academic Press: New York, 1984.

6. Castriciano, M. A.; Romeo, A.; Villari, V.; Angelini, N.; Micali, N.; Scolaro, L. M. J. of Phys. Chem. B 2005, 109, 12086.

7. Marquardt, D. W. J. Soc. Ind. Appl. Math. 1969, 11, 431.

8. Lakowicz, J. R. Principles of Fluorescence Spectroscopy; Kluwer Academic/Plenum Publishers: New York, 1999.

9. Sanchez-Sevilla, A.; Thimonier, J.; Marilley, M.; Rocca-Serra, J.; Barbet, J. UltraMicroscopy 2002, 151. 